\title{
STUDY ON EXPERIMENTAL MEASUREMENT OF BEHAVIORAL CHARACTERISTICS OF THE WORKERS IN NONSTATIONARY WORK
}

\author{
GENJI HOTTA ${ }^{1}$, TSUTAO KATAYAMA ${ }^{2}$, YASUNORI NAKAMURA ${ }^{3}$, \\ YOSHIFUMI OHBUCH ${ }^{4} \&$ HIDETOSHI SAKAMOTO ${ }^{5}$ \\ ${ }^{1}$ Ariake National College of Technology, Japan. \\ ${ }^{2}$ Doshisha University, Japan. \\ ${ }^{3}$ Osaka Sangyo University, Japan. \\ ${ }^{4}$ Kumamoto University, Japan. \\ ${ }^{5}$ Doshisha University, Japan.
}

\begin{abstract}
More than $50 \%$ of industrial accidents in the manufacturing industry are caused in nonstationary work. In nonstationary work, the worker's behavior characteristics appear most easily. If the behavioral characteristics are classified into some types and the feature and the danger of the type are recognized, they can be put in the safety management item, and the prevention of the disaster in nonstationary work becomes possible. Worker's action characteristics can be modeled as a combination in order of preference of three elements: risk prediction, risk avoidance and risk transmission. The behavioral characteristics of workers can also be modeled as the combination in order of preference with the aforementioned three elements. In previous research, it has been found that the models were classified as 14 kinds of behavior patterns. In this study, we report on the following research results. We have developed a testing apparatus to measure the consciousness level about risk prediction, avoidance and propagation, and the presence of 14 kinds of patterns of behavioral characteristics was verified. The relationships between the behavior type and the dangerousness, the behavior type and the mistake occurrence were examined experimentally.
\end{abstract}

Keywords: behavioral characteristic, human factor, infrequent operation, psychological tests, risk reduction, risk-taking situations

\section{INTRODUCTION}

Productive facilities keep their reliability by a routine check and maintenance procedure, generally carried out based on a check manual. In case of a breakdown of newly installed machinery, the repair manual cannot be sometimes found in the operation text. In the initial failure period of Bath Tub Curve, in particular, this tendency is remarkable. When 'Easy Repairing' is mentioned as a measure of the reliability in the mechanical equipment, it is indispensable to reduce the MTTR by immediate restoration of a breakdown at a production site. As there is no repair manual in the non-routine work, the repair operation is completely entrusted by a maintenance and operating engineer. This operation largely depends on the engineer's skill and experience [1]. However, in the non-routine operations, the correlation between the maintenance engineer's experience and the decrease in MTTR does not necessarily exist [2]. This is an important problem in the optimum maintenance planning. In this research, the analysis of the influence by the human factor on the reliability of machinery was carried out. And the reliability improvement of machinery by making reduction of the MTTR and the repair time was discussed. 


\section{ACTION MODEL OF THE MAINTENANCE ENGINEER UNDER THE BREAKDOWN}

\subsection{Conventional study about the reliability and human risk}

The research of the past about the influence by the human factor on the reliability of machinery are as follows: 1) the quality engineering analysis about the reliability of software in design review process [3]; 2) the occurrence pattern of human error in the marine vessel's engine trouble [4]; and 3) the system reliability analysis about the relation between a human behavior and a machinery breakdown, etc. In the conventional study, a human error is defined as a factor of the reliability in a model of a man machine system and its countermeasure is considered. In this research, we paid attention to the personality-like individuality behavioral characteristic of the maintenance engineer, not a human error as the risk factor affected to the reliability of the machine. These are pre-behavior, current behavior and post-behavior of the human at a breakdown.

\subsection{The influence of a personal behavior model on the reliability}

According to Japanese preservation society, the operating engineer's behavior at a breakdown was classified into three parts: 1) planning, 2) action, and 3) evaluation [6]. These are pre-behavior, current behavior and post-behavior at a breakdown. 'Evaluation' is the report of the breakdown cause and the repair treatment, and the collection of the information for the prevention of recurrence. As the reliability of mechanical system is decided by the combination of these three behavior's items, we define each behavioral element of a maintenance engineer as $K_{1}, K_{2}$ and $K_{3}$, respectively. A machine causes $\mathrm{N}$ times breakdown during a fixed period, and we assume that different maintenance engineers handle each breakdown. A set of choices for repair behavior were given to each maintenance engineer. We assign the number to each maintenance engineer of $N$ person and consider the next assembly.

$$
I=\{1,2,3, \cdots, N\}
$$

The behavior choices $(\mathrm{a}, \mathrm{b}, \cdots)$, which a maintenance engineer decides, exist in each behavior element $K n(n=1,2,3)$. So, the next system is formed.

$$
K_{n}^{I}=\left\{a_{n}^{I}, b_{n}^{I}, c_{n}^{I} \cdots\right\}(\mathrm{n}=1,2,3 \cdots)
$$

As a result, the repair time at each behavioral element is determined when a maintenance engineer selects the repair behavior. For example, when he selects the behavior of $K I$ (plan) stage, the assembly $T_{K I}$ of all repairing time is represented as the following system.

$$
T_{K I}^{I}=\left\{t_{K I}{ }^{1}, t_{K I}{ }^{2}, t_{K I}{ }^{3} \cdots\right\}
$$

When we assume the assembly which collects the repair time as the result of executing all of the three behavior elements to be $R^{I}$

$$
R^{I}=\left\{\left(T_{K 1}^{1}+T_{K 2}{ }^{1}+T_{K 3}{ }^{1}\right),\left(T_{K 1}{ }^{2}+T_{K 2}{ }^{2}+T_{K 3}{ }^{2}\right) \cdots\right\}
$$

Because the selecting from a number of repair method candidates becomes a decision-making problem [7]. 


\section{BEHAVIOR PATTERN CHECK OF THE MAINTENANCE ENGINEER}

\subsection{Operation of running in vehicle experiment machine}

The experiment machine makes the vehicle run from the starting point to the terminal so that the testee may operate the vehicle on a straight line orbit. It is tempering with the element of the game, which competes for time until putting it in the garage without an accident overcoming a trouble on the way. It is assumed here as follows. The vehicle transmits the risk of running to an oncoming car while repeating the risk forecast and the risk exclusion in service. A continuous design business can be simulated by continuous running operation to some degree. The reasons of selecting the orbit type are that the minimization of the parameter of the measurement is easy because the flexibility of the vehicle is 1 , and testee's interest induction. The experiment device $2.5 \mathrm{~m}$ in total length was divided into three sections as in Fig. 1.

The first section is the section that expects a risk while running in risk prediction section, and there is a flat straight railway track. The second section is a risk aversion section, and a rising orbit and a convex orbit are set as obstacle. In the third section, the model of the oncoming car is arranged and the situation of passing each other is imitated.

It is necessary to slow down in front of an oncoming car, and to blink the headlamp to report a risk surely. The testee does the drive operation of the vehicle by using the operation grip, which is attached to the orbit. The vehicle runs the three sections as shown in Fig. 1. The running operation of the vehicle is done by using the operation grip installed in the orbit. The vehicle is driven by increasing and decreasing little by little the inclination angle of the orbit. It is considered that worker's intention appear easily directly to the action in this experiment. This experiment model was differentiated with a general car drive model, and the influence that the operating experience had on the measurement result was excluded. The acceleration of up and down moving of testee's hand was measured by the acceleration sensor on the vehicle as shown in Fig. 2, and the measurement signal was recorded into a personal
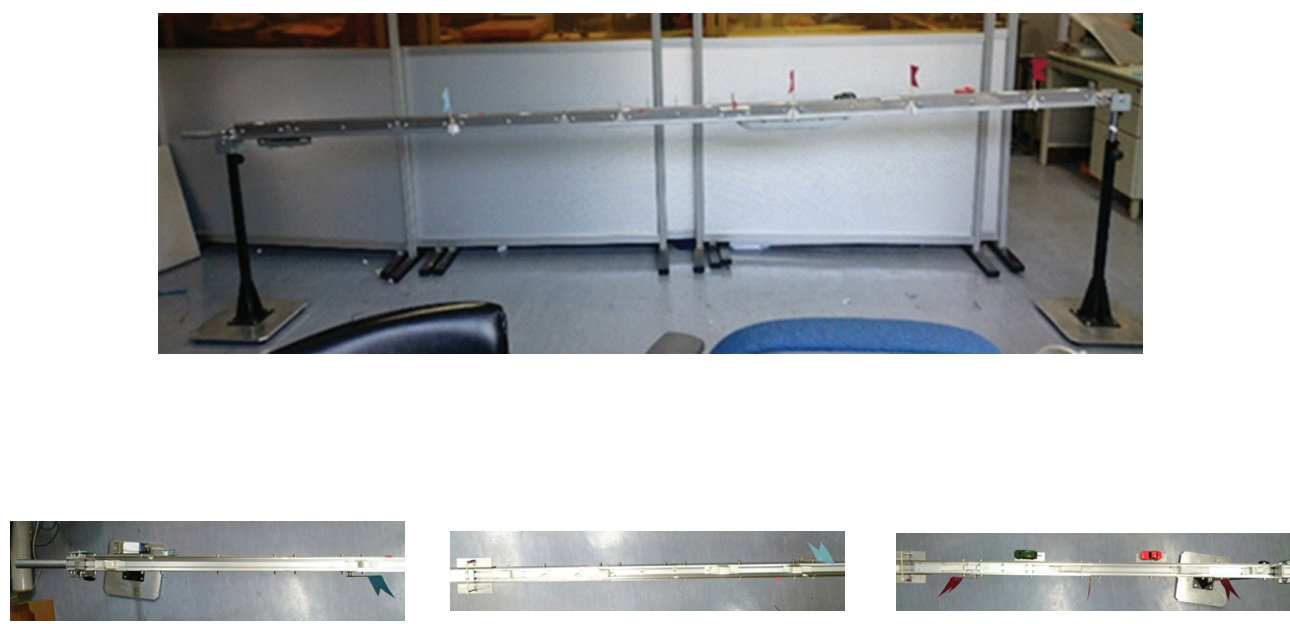

Figure 1: Testing equipment for the action properties measurement. (a) Predictive section; (b) Dangerous section; (c) Transmission section 


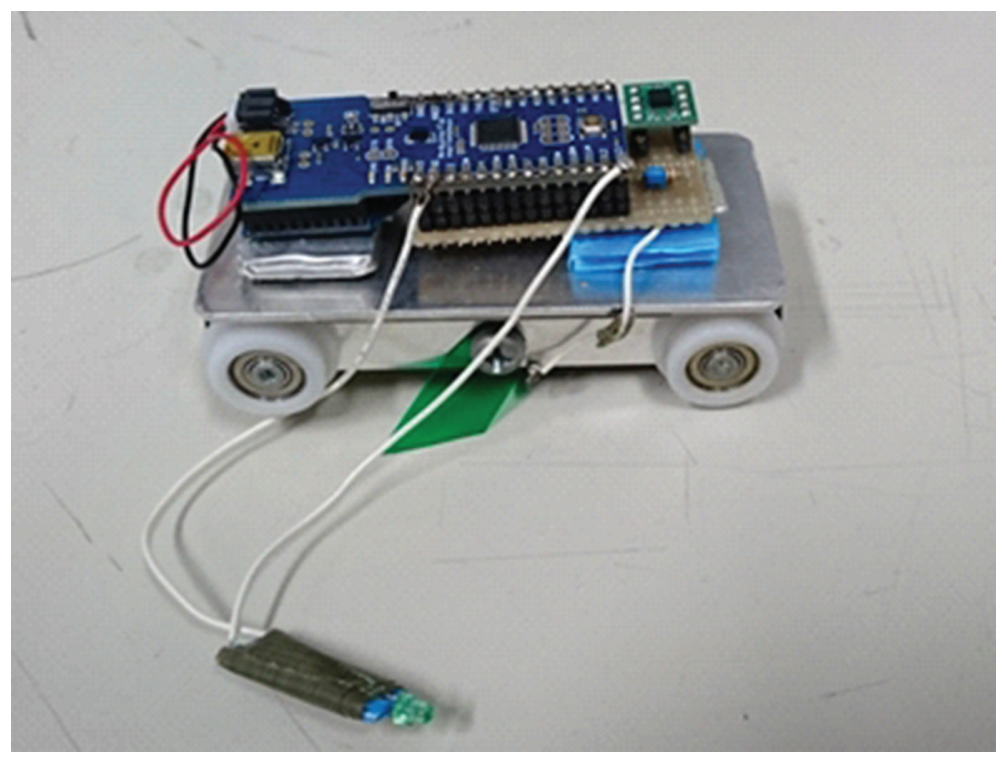

Figure 2: A vehicle and deployment parts.

computer by the wireless. The neodymium magnet is set up on the orbit in the delimitation of the section. The delimitation detects with the proximity sensor installed in the vehicle and is displayed. Moreover, the acceleration sensor was installed in the vehicle too.

The running direction's acceleration (direction of $\mathrm{x}$ ) and the tangential acceleration (direction of $\mathrm{z}$ ) in the circular arc that vehicle draws along with orbital inclination were measured. The acceleration wave and the delimitation section signal are recorded into the personal computer. The specification of the acceleration sensor and the delimitation detect switch are shown in Table 1.

\subsection{Quantification of the high consciousness for the risk}

As for the height of consideration to the risk forecast, the risk exclusion, and the risk transmission of the testee, it is thought that the trial-and-error is piled up the more seriously as follows events; the working hours in each section is long, the acceleration at the addition and subtraction velocity of the vehicle is large, and the frequency at the addition and subtraction velocity of the vehicle is large. The height of consciousness concerning the risk was shown by the numerical value in the working hours, the pulse height, and the cycle of the acceleration wave as parameters. It was assumed that the height of the testee's consciousness to three basic

Table 1: Specifications of deployment parts.

\begin{tabular}{lll}
\hline Parts & Model number & Maker \\
\hline Acceleration sensor & AE-ADXL335 & AKIDUKI \\
Proximity switch & MKA-10110 & SYNTEXTECH CP \\
Communications equipment & DIGI-XB24-CZ7PIT-004 & SWITCH SCIENCE \\
\hline
\end{tabular}


action elements was shown by a dimensionless number as the following strength rate, because it is necessary to compare the numerical value of the height of the measured consciousness. The strength rate is known as a function which shows the maintenance level and the severity of disaster quantitatively, and applied to the height of consciousness this time.

$$
\lambda_{n}^{\mathrm{I}}=\left\{\frac{t_{n}^{\mathrm{I}}}{\sum t_{n}^{\mathrm{I}}}+\frac{\alpha_{n}^{\mathrm{I}}}{\alpha_{0}}+\frac{T_{m}}{\sum t_{n}^{\mathrm{I}}}\right\} 100
$$

Here, eqn (4), $\lambda_{n}^{I}(n=1,2,3)$ shows the strength rate in each section.

$\lambda_{1}^{\mathrm{I}}$ is high risk predictive consciousness

$\lambda_{2}^{\mathrm{I}}$ is high risk aversion awareness

$\lambda_{3}^{2}$ is high risk transmission awareness

In addition, $\mathrm{t}_{\mathrm{n}}^{\mathrm{I}}(\mathrm{s})(\mathrm{n}=1,2,3)$ is the operation time in each section on the orbit of experiment device in testee $\mathrm{I}$. $\Sigma \mathrm{t}_{\mathrm{n}}^{\mathrm{I}}(\mathrm{s})$ is the total operation time of testee $\mathrm{I}$, and we can calculate it in eqn (5).

$$
\sum t_{n}^{\mathrm{I}}=t_{1}^{\mathrm{I}}+t_{2}^{\mathrm{I}}+t_{3}^{\mathrm{I}}
$$

$\alpha_{\mathrm{n}}^{\mathrm{I}}\left(\mathrm{m} / \mathrm{s}^{2}\right)$ is acceleration of the vehicles in the sections that testee I operates. $\alpha_{0}$ is derailment acceleration. It is measured beforehand as $\alpha_{0}=1200\left(\mathrm{~m} / \mathrm{s}^{2}\right)$.

$\mathrm{Tm}(\mathrm{s})$ is a mean cycle of the acceleration wave and is calculated in eqn (6).

$$
T_{m}=\frac{\sum T_{N}}{N}
$$

$T_{N}$ is the cycle time of acceleration and deceleration. $N$ is the number of times of acceleration and deceleration. We check the size order of three kinds of $\lambda_{\mathrm{n}}^{\mathrm{I}}$, and the type of the action characteristic of testee $\mathrm{I}$ is shown by all ordered set eqn (7).

$$
\mathrm{C}^{\mathrm{I}}=\left(\lambda_{\mathrm{n}}^{\mathrm{I}} \leqq\right)
$$

Then, we can express the model of action properties of subject I by the set. In addition, the risk level concerning the type of the action characteristic of testee I is presented by the risk number rate $\kappa$ of eqn (9).

$$
\kappa^{\mathrm{I}}=\left\{\frac{N_{1}^{\mathrm{I}}+N_{2}^{\mathrm{I}}}{\sum t_{n}^{\mathrm{I}}}\right\} 100
$$

$N^{I}$ is the number of times of the mistake of the testee, $N_{2}^{\mathrm{I}}$ is the number of times of the violation of the testee. The dangerous prime number rate was already verified in a precedent study (3). So, the action characteristic and the dangerous level of testee I is presented quantitatively by eqn (9) based on the action type $\mathrm{C}^{\mathrm{I}}$ and dangerous level $\kappa^{\mathrm{I}}$.

$$
\mathrm{A}^{\mathrm{I}}=\left(\mathrm{C}^{\mathrm{I}}, \kappa^{\mathrm{I}}\right)
$$

$\mathrm{A}^{\mathrm{I}}$ in eqn (9) can expect plural kinds. To facilitate distinguishing, the sign (I, II ‥XIII) is put from the ascending order $\kappa^{\mathrm{I}}$ (safe order). 


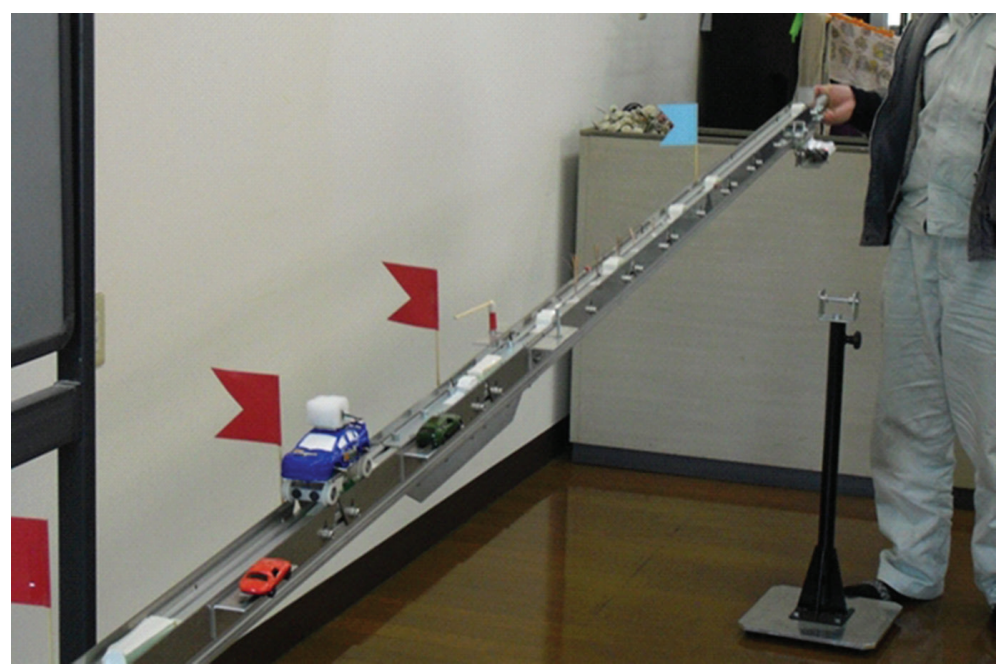

Figure 3: State of the experiment.

\subsection{Measurement by experiment device}

The experiment was executed by 44 Mechanical Engineering students of the Ariake National College of Technology and 28 employees of the Yamamoto Seisakusho Co. Ltd. The questionnaire after experiment was not executed this time. Figure 3 shows the appearance of the experiment. To improve the reliability of the acquisition data, the time trial race type was adopted in this experiment. The motivation improvement of the testees was pressed by publishing the experiment result and putting out the prize.

The data of the vehicle under running is displayed on the notebook computer as a graph (ordinate axis: accelerations: abscissa axis:time) according to the $\mathrm{x}, \mathrm{y}, \mathrm{z}$ directions on the note PC. The amplitude and the number of vibrations of accelerations in each section are measured and displayed. The parameter of eqns (6-8) is understood as follows by analyzing these waves.

Operation time in each orbit section $\mathrm{t}_{\mathrm{n}}^{\mathrm{I}}$ : the time between the magnets on horizontal axis in $\mathrm{x}$ direction wave[s].

$\alpha_{n}$ : the acceleration amplitude in the $\mathrm{x}$ direction $\left(\mathrm{m} / \mathrm{s}^{2}\right)$.

$T_{N}$ : the each section's cycle time of the acceleration and the deceleration in the $\mathrm{x}$ direction (s).

And in eqn (5),

$N^{\mathrm{I}}{ }_{1}$ : the number of times of the mistake, that is, the number of times of the derailment wave patterns in the y direction.

$N^{\mathrm{II}}{ }_{1}$ : the number of times of the violation, that is, the number of deviation acceleration wave patterns in the $\mathrm{z}$ direction.

\section{RESULT OF THE EXPERIMENT}

Figure 4 shows the example of the measurement wave pattern. The waves consist of undulation and a minute vibration. A micro vibration is due to the vibration of the running train 


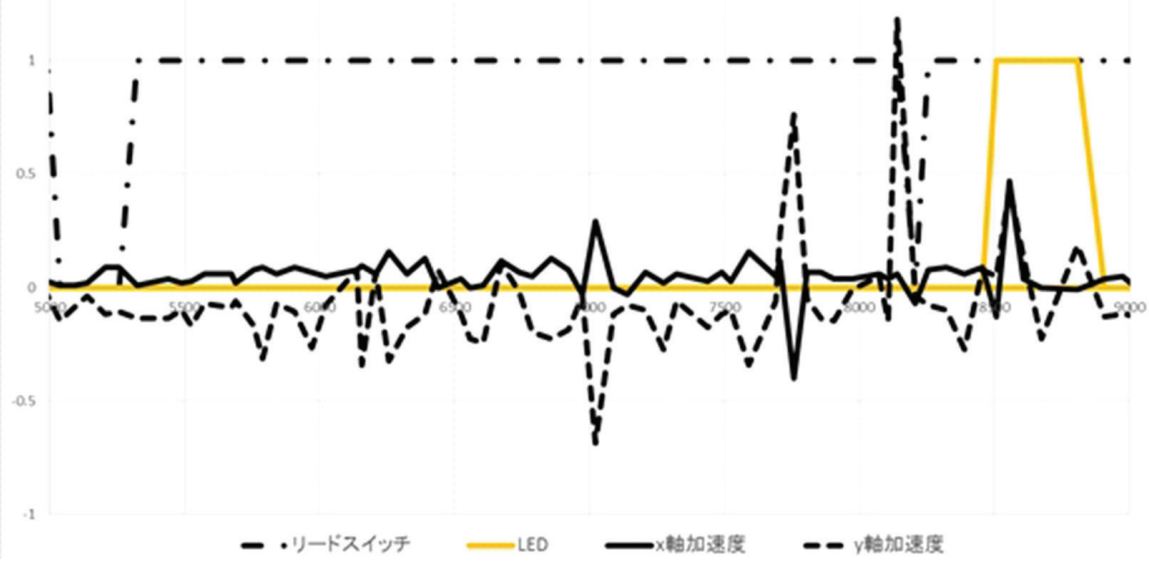

Figure 4: The measurement waveform that I got from a vehicle.

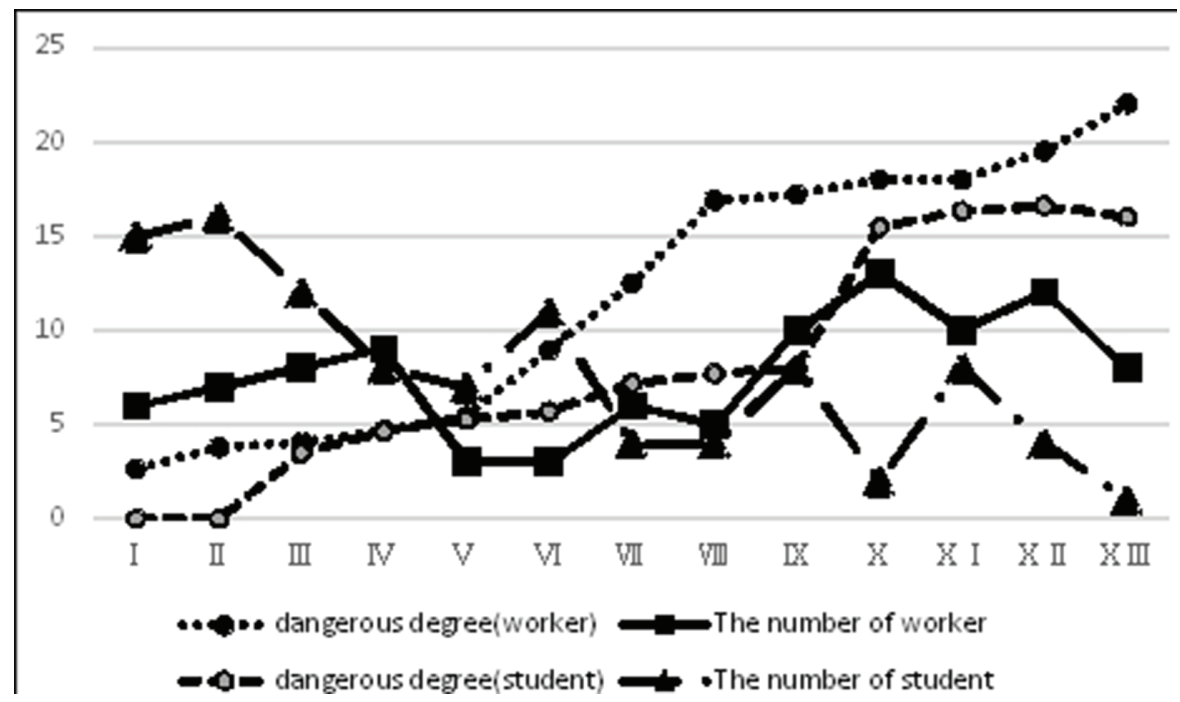

Figure 5: Number of people distribution about a model and the degree of risk of the action.

body. The undulation was analyzed because it was assumed that the part of undulation showed testee's action characteristics. Figure 5 shows the type $\mathrm{C}$ of action characteristics, the dangerous degree $\kappa$ and the number of testees. As for type I- X III of the action, the action characteristic pattern was classified as shown in Table 2 from the authors' experiments and others. 
Table 2: Pattern of behavioral Characteristic model.

\begin{tabular}{|c|c|c|}
\hline $\begin{array}{l}\text { behavioral } \\
\text { characteristic }\end{array}$ & $\begin{array}{l}\text { Preference } \\
\text { relation }\end{array}$ & Characteristic of the model \\
\hline I & (1) (2) (3) & Almighty type \\
\hline II & (3) $\succ$ (1) $\succ$ (2) & Cooperation type \\
\hline III & (1) $>$ (2) $>$ (3) & Reliable model \\
\hline IV & (1) (2) $>$ (3) & Model to be captivated by \\
\hline $\mathrm{v}$ & (1) $>$ (3) $>$ (2) & Mature deliberation type \\
\hline V I & (1) $>$ (2) (3) & Carefulness type \\
\hline VII & (2) $\succ$ (1) $\succ$ (3) & No consideration type \\
\hline VIII & (3) $>$ (2) $>$ (1) & Dependence type \\
\hline IX & (1) $\sim$ (3) $>$ (2) & Hyperconsideration type \\
\hline $\mathrm{x}$ & (3) $\succ$ (1) (2) & Hypercarefulness type \\
\hline $\mathrm{XI}$ & (2) $\succ$ (3) $\succ$ (1) & Carelessness type \\
\hline $\mathrm{XII}$ & (2) (3) $>$ (1) & Mild model \\
\hline $\mathrm{X} I I I$ & (1) $\forall$ (2) $\nsucc$ (3) & Unconsciousness type \\
\hline XIV & (2) $>$ (1) (3) & Risk taking type \\
\hline
\end{tabular}

\section{CONCLUSIONS}

Authors thought that the exteriorization of action properties in the nonstationary work was a factor of the work-related accident. Therefore, it was decided that engineering checked action properties of the worker as for us experimentally.

In this study, the work model to extract basic work in three stages was proposed. High consciousness of the risk aversion of the object was measured through the three-phase of basic work and the frequency of the mistake. As a result, the relation between the testee's action characteristic and its risk level was clarified.

A vehicle run-operation experiment device was developed to check the risk aversion behavior. The experiment was executed by 44 Mechanical Engineering students of the Ariake National College of Technology and 28 employees of the Yamamoto Seisakusho Co. Ltd. The experiment result showed that the action characteristic of work was different according to the testee's experience. Those action characteristics were classified into 13 types in the order of safety according to the level of danger. The company's testees have the tendency of high dangerous action characteristics as compared with the student's testees in the relation between the action characteristic and the number's distribution of testee and the dangerous risk level. This was the same as conventional findings of the authors.

Therefore, some reliable result without using a questionnaire can be derived by using the proposed experimental device. In addition, authors already confirmed that the risk evasion ability improves by giving the education and training to the worker who has a dangerous action characteristic. It can be expected that there is a similar effect for the engineer who has a dangerous action characteristics in the design work, and the action characteristic analysis that were carried out in this study is applicable to desk work too. 


\section{REFERENCES}

[1] Sugimoto, H., Maintenance work and safety for production machine. Reliability Engineering Association of Japan, 25(7), pp. 690-694, 2003. https://doi.org/10.1016/j.ress.2016.11.001

[2] Baba, F., Research on the sTable equipment maintenance activities based on the PDCA cycle - The information link and division by class of a production activity as the foundation. YOKOHAMA International Society Study Research, 2(2), pp. 210-211, 2012.

[3] Esaki, K., Yamada, S., Takahashi, M. \& HIhara, K., A quality engineering approach to human factors affecting software reliability in design process. The Journal of the Institute of Electronics, Information and Communication Engineers, J83-A(7), pp. 875-882, 2000.

[4] Najamura, M., Analysis of human errors in marine engine accidents. Research Reports of the Yuge National College of Maritime Technology, 34, pp. 14-19, 2012.

[5] Matuoka, T., System reliability analysis in consideration of human action and an equipment failure-Approach by the GO-FLOW technique, available at http://www.mech.utsunomiya-u.ac.jp/safety/gf_mmi.htm, 2013

[6] Japan Society Maintenology. Examination about a preservation program and an inspection. The Data of Investigative Commission about the State of the 20th Inspection, pp. 6-11, 2006.

[7] Atunobu, I., Theory of decision making. Kyoritu Shuppan Co. Ltd, pp. 4-7, 1983. 